\title{
Idiopathic hypertrophic subaortic stenosis with and without mitral regurgitation Phonocardiographic differentiation from rheumatic mitral regurgitation
}

\author{
Keith M. Lindgren and Stephen E. Epstein \\ From the Cardiology Branch, National Heart and Lung Institute, Bethesda, Maryland 20014, \\ U.S.A.
}

The murmur of idiopathic hypertrophic subaortic stenosis has been confused with that of mitral regurgitation due to rheumatic heart disease. To determine if these two entities can be consistently differentiated, phonocardiograms were studied in $4 I$ patients with idiopathic hypertrophic subaortic stenosis with and without mitral regurgitation and compared to $I 7$ patients with rheumatic mitral regurgitation. All patients with rheumatic mitral regurgitation had holosystolic murmurs beginning with $S_{1}$ and ending at or after $A_{2}$. In idiopathic hypertrophic subaortic stenosis the murmur either began after $S_{1}$, ended before $A_{2}$, or both, in all but one patient in whom the mitral regurgitation persisted after operative relief of outflow obstruction. We conclude that the duration of the recorded murmur is valuable in distinguishing patients with idiopathic hypertrophic subaortic stenosis with or without mitral regurgitation from those with rheumatic mitral regurgitation. A true holosystolic murmur in a patient with idiopathic hypertrophic subaortic stenosis suggests that organic disease of the mitral valve may coexist, in which case mitral regurgitation may persist despite successful operative relief of obstruction.

Mitral regurgitation often is present in patients with idiopathic hypertrophic subaortic stenosis, its frequency in various series ranging from 40 to roo per cent (Braunwald et al., 1964; Cohen et al., 1964; Criley et al., 1965; Wigle et al., 1969). Since the apical systolic murmur in such patients is interpreted frequently as being holosystolic (Friedberg, 1966), many patients with idiopathic hypertrophic subaortic stenosis have been misdiagnosed as having rheumatic mitral regurgitation. However, it has been suggested recently that the apical murmur of patients with idiopathic hypertrophic subaortic stenosis and mitral regurgitation ends before the aortic component of the second sound (Harris, Donmoyer, and Leatham, I969). In order to determine if the murmur in patients with

- idiopathic hypertrophic subaortic stenosis and mitral regurgitation, (I) can be distinguished consistently from that due to rheumatic mitral regurgitation, and (2) differs from that present in patients with idiopathic hypertrophic sub-

Received 5 April I97I. aortic stenosis but without mitral regurgitation, we analysed the phonocardiograms of patients with idiopathic hypertrophic subaortic stenosis, who had angiographic documentation of the presence or absence of mitral regurgitation.

\section{Methods}

Data were reviewed in 113 patients admitted to the National Heart and Lung Institute and diagnosed as having idiopathic hypertrophic subaortic stenosis according to criteria published previously (Braunwald et al., 1964). Of this group, 4I had angiographic evaluation of mitral regurgitation and adequate phonocardiographic tracings for review. Mitral regurgitation was graded on a scale of mild, moderate, or severe. The phonocardiograms were recorded with a Sanborn polybeam photographic recorder at a paper speed of $75 \mathrm{~mm} / \mathrm{sec}$ using a crystal microphone and a Sanborn heart sound preamplifier (Model 350 I799B). Recordings were made with high frequency filters at 200 and $400 \mathrm{cps}$. The indirect carotid pulse tracing was obtained with a $2.5 \mathrm{~cm}$ diameter funnel connected by an air column to a 
crystal pickup or a strain gauge with a carrier preamplifier.

The phonocardiograms were reviewed in the following manner. Segments of the phonocardiograms (which contained sound tracings obtained from the cardiac apex and a recording of the carotid pulse) were separated from the remainder of the record and assembled randomly. They were then analysed without knowledge of the diagnosis. The systolic ejection time and the interval from the upstroke of the carotid pulse to the first peak were measured. The ejection time was corrected for heart rate by dividing by the square root of the $\mathbf{R R}$ interval. The onset of the systolic murmur at the apex was timed from the onset of the first sound. This period was designated the $S_{1}$-murmur interval. Occasionally the first sound was not recorded at the apex and this measurement could not be made. The systolic murmur was judged to end before the aortic closure sound if we could identify a definite period that was as free of vibration as a stable baseline tracing during diastole. Phonocardiograms in which the baseline contained excessive noise were excluded from the study. The period between the last vibration of the murmur and the first vibration of the second sound was measured to the nearest $0.01 \mathrm{sec}$ and designated the murmur- $\mathrm{A}_{2}$ interval. Measurements were averaged over approximately five cycles. No attempt was made to grade the intensity of the murmurs since they were recorded at different amplifications.

For comparison, 17 consecutive patients with catheterization documented mitral insufficiency not associated with idiopathic hypertrophic subaortic stenosis and believed to be due to rheumatic heart disease were reviewed. Their phonocardiograms were analysed in an identical manner.

\section{Results}

The apical systolic murmur recorded in patients with idiopathic hypertrophic subaortic stenosis but without mitral insufficiency was crescendo-decrescendo in type. It clearly began after the first sound in 17 of the 20 cases. In I patient the murmur began with $S_{1}$, and in 2 patients $S_{1}$ was not recorded. The average interval from $S_{1}$ to the onset of the murmur was $0.09 \mathrm{sec}$ (Fig. I). The murmur ended before the sound of aortic closure in all patients and the interval from the end of the murmur to $\mathbf{A}_{2}$ averaged $0.05 \mathrm{sec}$ (Fig. I).

In patients with idiopathic hypertrophic subaortic stenosis and mild mitral insufficiency, the onset of the murmur was separated from $S_{1}$ in all instances (Fig. I). The murmur ended at least $0.02 \mathrm{sec}$ before $\mathrm{A}_{2}$, with one exception (Fig. I); in this patient there was a clear interval of $0.08 \mathrm{sec}$ from $S_{1}$ to the onset of the murmur (Fig. 2). The interval between the end of the murmur and $A_{2}$ was as great as $0.04 \mathrm{sec}$ in 3 of these 8 patients.

In patients with idiopathic hypertrophic subaortic stenosis and moderate mitral insufficiency the murmur was crescendo-

FIG. I Interval from first heart sound to onset of the apical systolic murmur and interval from the end of the apical systolic murmur to $A_{2}$ in patients with idiopathic hypertrophic subaortic stenosis with and without mitral regurgitation and in patients with rheumatic mitral regurgitation.
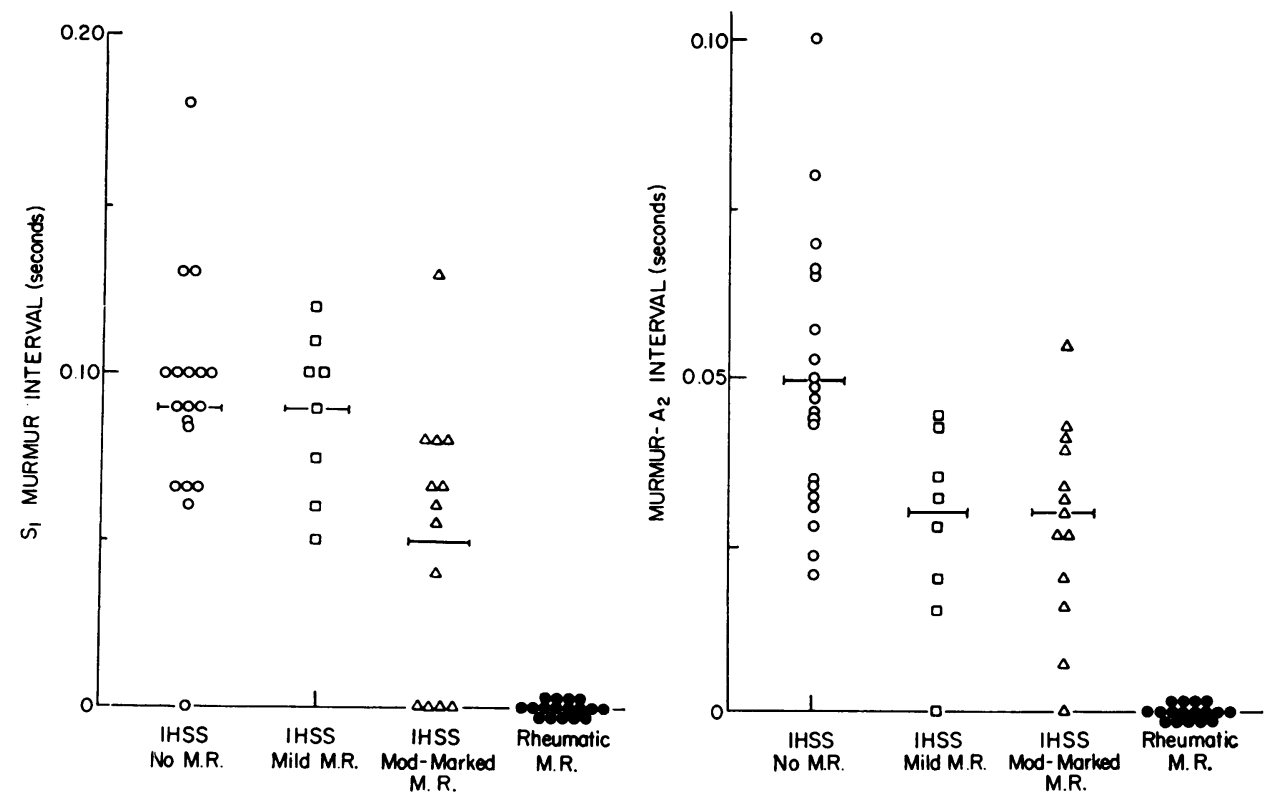
decrescendo in all 13 patients and in 9 it was definitely midsystolic (i.e. a clear interval was demonstrable between $S_{1}$ and the onset of the murmur and between the end of the murmur and $A_{2}$ (Fig. 3)). In 3 patients the murmur began with $S_{1}$ but ended before $A_{2}$. Vibrations were recorded from $S_{1}$ to $A_{2}$ in only one patient in the entire series (Fig. 4). Though this fulfils the criteria for a holosystolic murmur, midsystolic accentuation was quite striking.

Thus, neither the contour of the murmur, nor its relation to $S_{1}$ or $A_{2}$ enabled us to distinguish between the patients with idiopathic hypertrophic subaortic stenosis and mild mitral regurgitation from those with moderate or conspicuous regurgitation. Furthermore, the phonocardiographic features of the murmur in these groups were indistinguishable from those of patients with idiopathic hypertrophic subaortic stenosis but no mitral regurgitation. A possible exception to this latter statement was the finding that mitral regurgitation was present in the only 2 patients in whom the murmur continued to $\mathbf{A}_{2}$.

By comparison, all patients with mitral insufficiency due to rheumatic heart disease had systolic murmurs at the apex that began with $S_{1}$ and clearly continued to aortic closure (Fig. 1). The holosystolic duration of these murmurs was an important feature since midsystolic accentuation of the murmur, similar to that observed in patients with idiopathic hypertrophic subaortic stenosis, was noted in several of these patients.

The corrected systolic ejection time of these groups is presented in Fig. 5. Normal values were obtained from the data of Harris et al. (1969). All three groups with idiopathic hypertrophic subaortic stenosis had a mean ejection time that was greater than normal. No significant shortening of the systolic ejection time occurred in the group of idiopathic hypertrophic subaortic stenosis with mitral regurgitation. In contrast, the group with mitral regurgitation not associated with idiopathic hypertrophic subaortic stenosis had a mean ejection time that was significantly shorter than the groups with idiopathic hypertrophic subaortic stenosis $(P<0 \cdot 001)$. Despite the differences between the groups in mean values, the range of individual values showed considerable overlap.

Since the carotid pulse of patients with idiopathic hypertrophic subaortic stenosis manifests a rapid onset to first peak, and since these patients tend to have a systolic ejection time that is longer than patients with rheumatic mitral regurgitation, a ratio of the onset

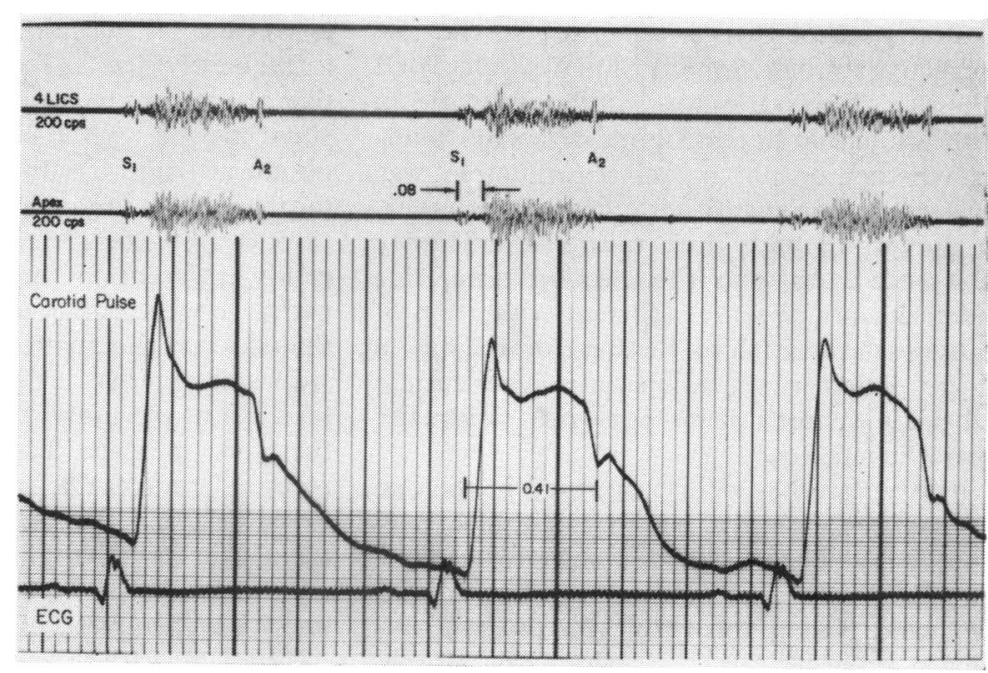

FIG. 2 Recording obtained from a patient with idiopathic hypertrophic subaortic stenosis and mild mitral regurgitation. Apical systolic murmur begins $0.08 \mathrm{sec}$ after $S_{1}$ but continues to $A_{2}$ Carotid pulse tracing shows early peak and prolonged ejection time.

FIG. 3 Recording obtained from a patient with idiopathic hypertrophic subaortic stenosis and moderate mitral regurgitation. Apical systolic murmur begins $0.08 \mathrm{sec}$ after $S_{1}$ and ends $0.04 \mathrm{sec}$ before onset of $A_{2}$.

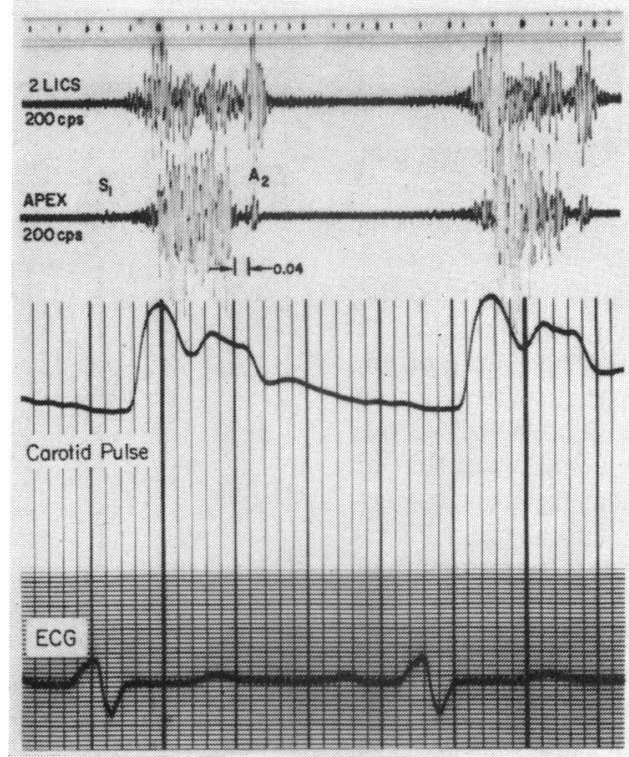


to first peak of the carotid pulse to the uncorrected systolic ejection time was calculated (Fig. 5). This ratio was similar in patients with idiopathic hypertrophic subaortic stenosis whether or not mitral regurgitation was present. It was significantly greater, however, in the group with pure mitral insufficiency $(P<0.001)$. As with the ejection time, this index did not provide sufficient separation of individual patients to distinguish reliably a given patient with idiopathic hypertrophic subaortic stenosis from one with rheumatic mitral insufficiency.

Further studies were performed in the one patient in this series with idiopathic hypertrophic subaortic stenosis, mitral insufficiency, and a holosystolic murmur (Fig. 4). On squatting, the intensity of the murmur recorded along the left sternal edge diminished, while the apical murmur was unchanged or increased slightly. Because of severe symptomatic limitation, a left ventricular myotomy and myectomy were carried out; no procedure on the mitral valve was performed. Six months after operation the patient was asymptomatic. A phonocardiogram recorded at this time showed a cylindrically-shaped holosystolic murmur at the apex identical to that seen in rheumatic mitral regurgitation (Fig. 4). On repeat cardiac catheterization no gradient across the outflow tract of the left ventricle was found even after infusion of isoprenaline or during the Valsalva manoeuvre. Moderate mitral regurgitation was documented angiographically. These findings were interpreted as being compatible with the hypothesis that organic disease of the mitral valve was present in addition to idiopathic hypertrophic subaortic stenosis.

\section{Discussion}

The present investigation clearly shows that the apical systolic murmur in patients with idiopathic hypertrophic subaortic stenosis is rarely holosystolic, regardless of the presence or absence of mitral regurgitation. Thus, the murmur either begins after the first sound, ends before the second sound, or more often, manifests both of these characteristics. These findings are in general agreement with those of Harris and coworkers who reported that of 6 patients studied with idiopathic hypertrophic subaortic stenosis and angiographically documented mitral regurgitation, all had systolic murmurs which ended before the second sound (Harris et al., 1969).

It should be pointed out that in many patients the gap between the end of the murmur and $A_{2}$ was very narrow and often difficult to appreciate by auscultation. Though this not infrequently led to the clinical impression that the murmur was holosystolic, a distinct silent period was easily discernible on the phonocardiogram. In contrast, though the mean ejection time and the mean ratio of the carotid upstroke to ejection time were significantly different in those patients with idiopathic hypertrophic subaortic stenosis and those with rheumatic mitral regurgitation, sufficient overlap existed to prevent clear separation of individual values. Our data therefore indicate that the duration of the recorded murmur is much more valuable in distinguishing the individual patient with idiopathic hypertrophic subaortic stenosis, with or without mitral regurgitation, from one with rheumatic mitral insufficiency.

The fact that the apical systolic murmur in patients with idiopathic hypertrophic sub-

FIG. 4 Preoperative and postoperative recording obtained from the only patient with idiopathic hypertrophic subaortic stenosis and a true holosystolic murmur. Before operation the systolic murmur at the left sternal edge is much diminished by prompt squatting, while the apical murmur remains essentially unchanged (see text).

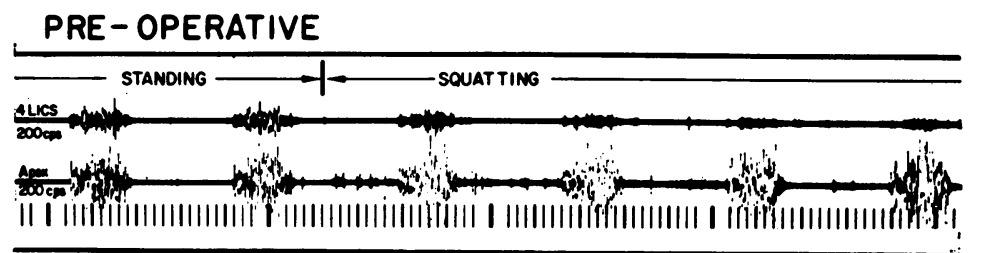

POST-OPERATIVE
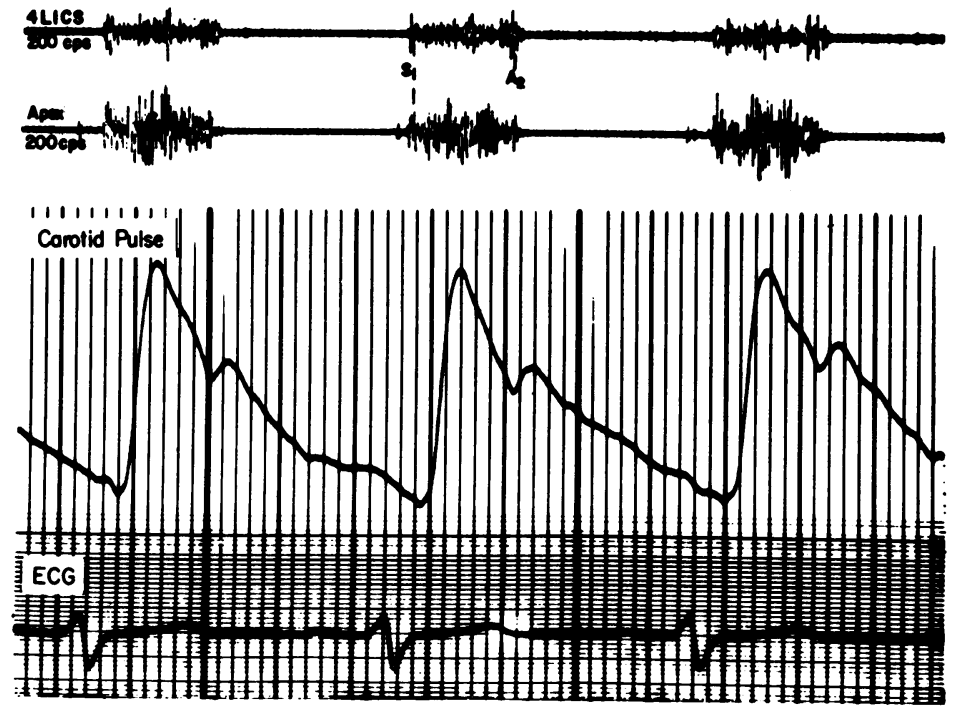

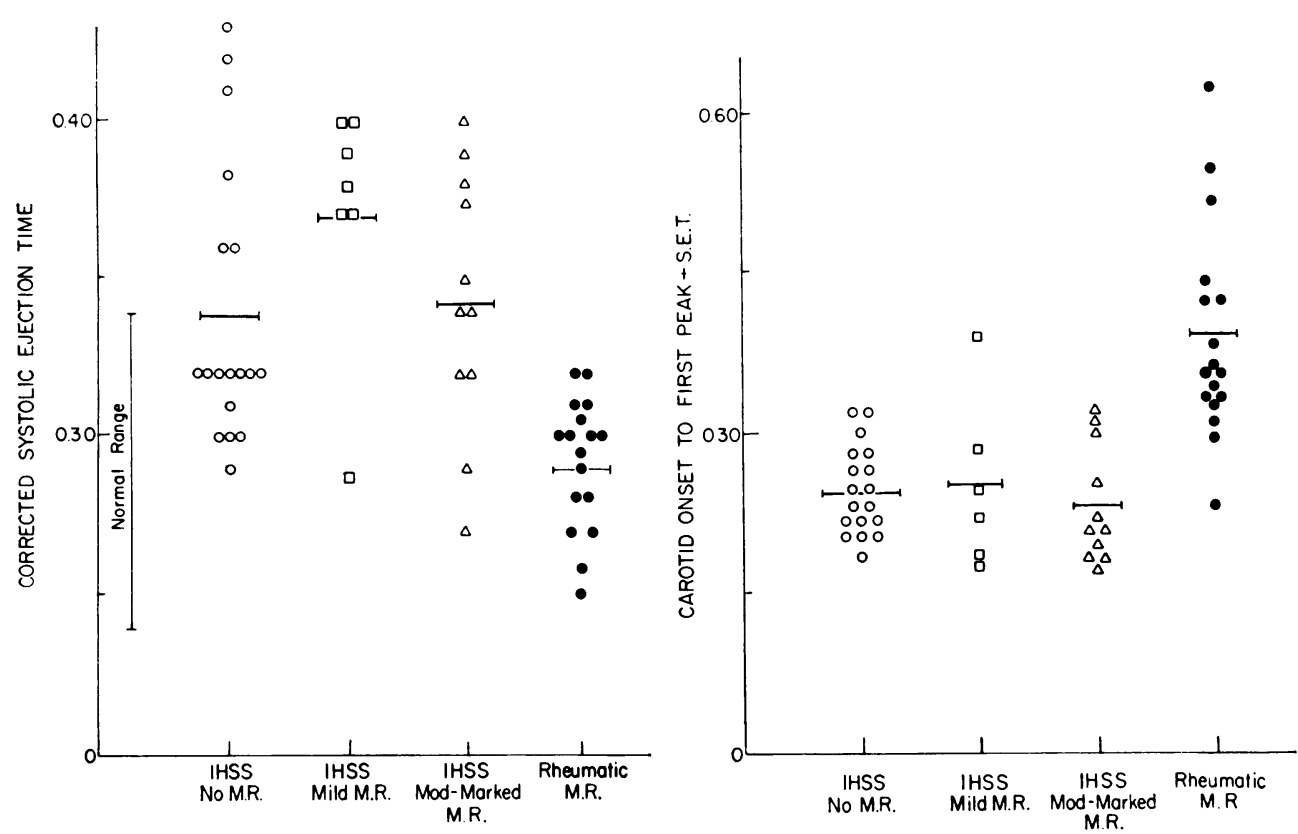

FIG. 5 Corrected systolic ejection time derived from carotid pulse tracings and ratio of onset of the carotid pulse to first peak divided by the systolic ejection time in patients with idiopathic hypertrophic subaortic stenosis with and without mitral regurgitation.

aortic stenosis and mitral regurgitation is not holosystolic suggests that its pathogenesis differs from that responsible for the mitral incompetence found in rheumatic valvular disease in which the apical systolic murmur is characteristically holosystolic. Alternatively, it is possible that the mitral insufficiency is silent in idiopathic hypertrophic subaortic stenosis and only an inflow tract midsystolic murmur is recorded. However, Fig. 6 depicts phonocardiographic tracings recorded simultaneously from the left atrium ${ }^{1}$ and chest wall in a patient with idiopathic hypertrophic subaortic stenosis and mild mitral regurgitation. The murmur recorded in the left atrium begins $0.08 \mathrm{sec}$ after $S_{1}$ and ends at least 0.04 sec before $A_{2}$. In addition, the atrial murmur is similar in timing and configuration to the apical murmur recorded from the chest wall. These findings suggest that mitral regurgitation in idiopathic hypertrophic subaortic stenosis is not silent but produces a midsystolic murmur in the left atrium.

As is well known, mitral regurgitation murmurs which are not holosystolic have been described in a number of situations other than

1 Dallons-Telco RA8 electromanometer with a MM5A52 micromanometer recorded on an Electronics for Medicine Photographic Recorder.
FIG. 6 Recording obtained from a patient with idiopathic hypertrophic subaortic stenosis with mild mitral regurgitation. Simultaneous chest wall phonocardiogram with left atrial sound and pressure recording. Murmur in left atrium begins $0.08 \mathrm{sec}$ after $S_{1}$, diminishes in late systole, and ends $0.04 \mathrm{sec}$ before $A_{2}$. Time interval markings denote $0.04 \mathrm{sec}$.

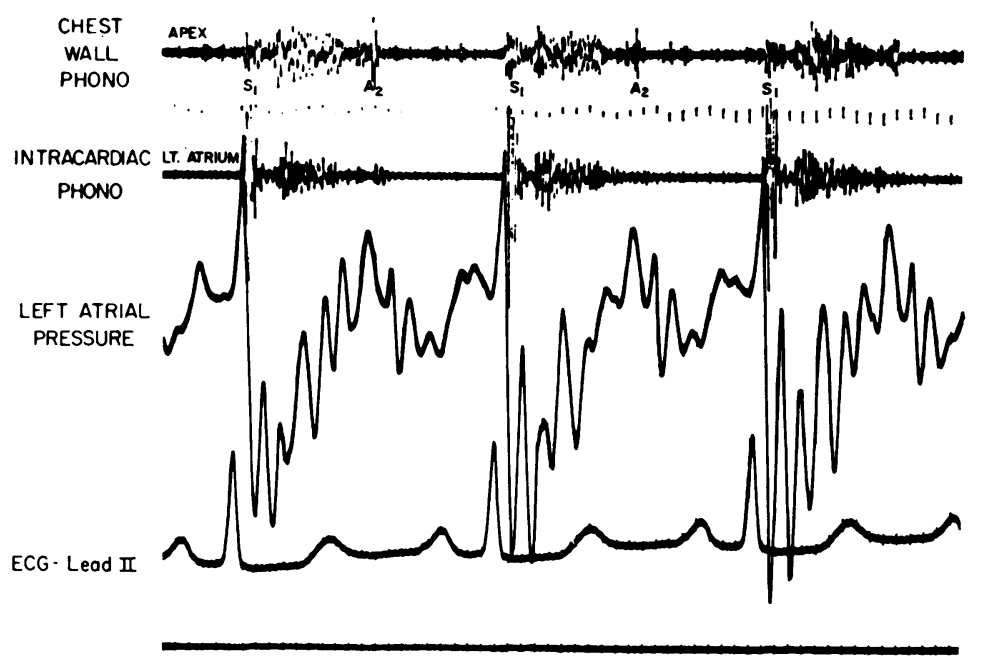


idiopathic hypertrophic subaortic stenosis. Sutton and Craige (1967) noted that in acute severe mitral insufficiency, regurgitation into a small, poorly distensible atrium caused left atrial pressure to approach left ventricular pressure in late systole, thus decreasing or eliminating the regurgitant flow and murmur before the end of systole. The left atrial V wave in the patient they reported was $60 \mathrm{~mm}$ $\mathrm{Hg}$. Since left atrial $\mathrm{V}$ waves averaged only $2 \mathrm{I}$ $\mathrm{mmHg}$ in the group of patients with idiopathic hypertrophic subaortic stenosis and mitral regurgitation included in this investigation, such a mechanism would not explain the early termination of the murmur in idiopathic hypertrophic subaortic stenosis. Another cause of mitral insufficiency that produces a murmur that is not holosystolic (Leon et al., 1966) but that does not appear to be applicable to idiopathic hypertrophic subaortic stenosis, is the mitral insufficiency due to prolapse of a redundant mitral leaflet (floppy valve syndrome). Pathologically no redundancy of the mitral valve has been found in patients with idiopathic hypertrophic subaortic stenosis.

Papillary muscle dysfunction results in an apical systolic murmur which occurs in either early, mid, or late systole (Shelburne, Rubinstein, and Gorlin, 1969). The mitral regurgitation present in this abnormality is due to interference with the normal function of the supporting structures of the mitral valve, rather than to an abnormality of the valve leaflets themselves. Similarly, the mitral incompetence occurring in patients with idiopathic hypertrophic subaortic stenosis also may be due to an interference with these supporting structures, i.e. it has been suggested that abnormal positioning of the papillary muscles during systole secondary to the asymmetrical hypertrophy of the ventricular septum produces traction on the anterior leaflet of the mitral valve such that it is pulled forward and abuts against the ventricular septum (Dinsmore, Sanders, and Harthorne, 1966; Adelman et al., 1969). Such a hypothesis is supported by ultrasound studies of the anterior leaflet of the mitral valve in patients with idiopathic hypertrophic subaortic stenosis. Instead of remaining in the normal posterior position throughout systole, the anterior leaflet reapproaches the septum after the aortic valve opens and returns to the posterior position in late systole (Shah, Gramiak, and Kramer, 1969; Pridie and Oakley, 1970). Based on such findings, the resulting mitral regurgitation would be expected to be midsystolic, and the murmur generated would therefore coincide in timing with the gradient and murmur produced by the midsystolic outflow tract obstruction. Additional evidence for this argument can be inferred from the observation that mitral regurgitation usually disappears after the muscular obstruction has been relieved either operatively, by myotomy or myectomy (Morrow et al., 1968), or pharmacologically, by infusing pressor agents and thereby increasing the distending pressure of the left ventricular outflow tract (Wigle et al., 1969).

The two patients with idiopathic hypertrophic subaortic stenosis in whom the systolic murmur engulfed $A_{2}$ are instructive. In one patient the murmur began after $S_{1}$. Thus, the phonocardiographic record clearly showed that the characteristics of the murmur were not those of rheumatic mitral regurgitation. The second patient provided the only example of a true holosystolic murmur in the $4 \mathrm{I} \mathrm{pa-}$ tients with idiopathic hypertrophic subaortic stenosis reviewed. In this patient, the holosystolic murmur recorded before operation had a crescendo-decrescendo configuration (Fig. 4). After operation, when the outflow obstruction was completely relieved, moderate mitral regurgitation persisted and the holosystolic murmur assumed a more cylindrical contour.

These findings suggest that organic valvular mitral insufficiency was present in addition to idiopathic hypertrophic subaortic stenosis, and that the murmur recorded before operation resulted from a superimposition of the outflow tract murmur of idiopathic hypertrophic subaortic stenosis and the holosystolic murmur of organic mitral insufficiency. Further evidence favouring this hypothesis was provided by the results obtained during squatting (Fig. 4): this manoeuvre caused no change or a slight increase in the murmur recorded at the cardiac apex, as would be expected if the pathogenesis of the murmur were similar to that of the murmur of rheumatic mitral insufficiency; in contrast, the left lower sternal border murmur was diminished with squatting, a finding typical of that observed in patients with idiopathic hypertrophic subaortic stenosis (Nellen et al., 1967).

Distortion and fibrosis of the mitral valve leaflets have been described in cases of idiopathic hypertrophic subaortic stenosis (Teare, 1958). The existence of an occasional patient with a holosystolic murmur, as found in this investigation, may therefore indicate that a functional organic valvular abnormality may coexist in a small number of patients with idiopathic hypertrophic subaortic stenosis, and that in these patients the possibility must be considered that some degree of mitral 
regurgitation may persist despite successful operative relief of the outflow tract obstruction.

\section{References}

Adelman, A. G., McLoughlin, M. J., Marquis, Y., Auger, P., and Wigle, E. D. (1969). Left ventricular cineangiographic observations in muscular subaortic stenosis. American fournal of Cardiology, 24, 689.

Braunwald, E., Lambrew, C. T., Rockoff, S. D., Ross, J., and Morrow, A. G. (I964). Idiopathic hypertrophic subaortic stenosis: I. A description of the disease based upon an analysis of 64 patients. Circulation, 29, Suppl. IV, 3.

Cohen, J., Effat, H., Goodwin, J. F., Oakley, C. M., and Steiner, R. E. (1964). Hypertrophic obstructive cardiomyopathy. British Heart fournal, 26, I6.

Criley, J. M., Lewis, K. B., White, R. I., Jr., and Ross, R. S. (I965). Pressure gradients without obstruction. Circulation, 32, 88I.

Dinsmore, R. E., Sanders, C. A., and Harthorne, J. W. (1966). Mitral regurgitation in idiopathic hypertrophic subaortic stenosis. New England fournal of Medicine, 275, 1225.

Friedberg, C. K. (1966). Diseases of the Heart. W. B. Saunders, Philidelphia and London.

Harris, A., Donmoyer, T., and Leatham, A. (1969). Physical signs in differential diagnosis of left ventricular obstructive cardiomyopathy. British Heart Fournal, 31, 501.

Leon, D. F., Leonard, J. J., Kroetz, F. W., Page, W. L., Shaver, J. A., and Lancaster, J. F. (1966). Late systolic murmurs, clicks, and whoops arising from the mitral valve. American Heart fournal, 72, 325 .
Morrow, A. G., Fogarty, T. J., Hannah, H., and Braunwald, E. (1968). Operative treatment in idiopathic hypertrophic subaortic stenosis: techniques and the results of preoperative and postoperative clinical and hemodynamic assessments. Circulation, 37, 589 .

Nellen, M., Gotsman, M. S., Vogelpoel, L., Beck, W., and Schrire, V. (1967). The effect of prompt squatting on the systolic murmur in idiopathic hypertrophic cardiomyopathy. British Medical Fournal, 3, I40.

Pridie, R. B., and Oakley, C. M. (1970). Mechanism of mitral regurgitation in hypertrophic obstructive cardiomyopathy. British Heart fournal, 32, 203.

Shah, P. M., Gramiak, R., and Kramer, D. H. (1969). Ultrasound localization of left ventricular outflow obstruction in hypertrophic obstructive cardiomyopathy. Circulation, 40, 3.

Shelburne, J. C., Rubinstein, D., and Gorlin, R. (1969). A reappraisal of papillary muscle dysfunction. American fournal of Medicine, 46, 862.

Sutton, G. C., and Craige, E. (1967). Clinical signs of severe acute mitral regurgitation. American fournal of Cardiology, 20, I4I.

Teare, D. (1958). Asymmetrical hypertrophy of the heart in young adults. British Heart fournal, 20, I.

Wigle, E. D., Adelman, A. G., Auger, P., and Marquis, Y. (1969). Mitral regurgitation in muscular subaortic stenosis. American fournal of Cardiology, 24, 698.

Requests for reprints to Dr. Stephen E. Epstein, Chief, Cardiology Branch, National Heart and Lung Institute Bldg. I0, Room 7B-15, Bethesda, Maryland 20014, U.S.A. 